\title{
Patient Experiences Using an Inpatient Personal Health Record
}

Janet Woollen ${ }^{1}$; Jennifer Prey ${ }^{1}$; Lauren Wilcox ${ }^{2}$; Alexander Sackeim³; Susan Restaino4; Syed T. Raza4; Suzanne Bakken ${ }^{1,5}$; Steven Feiner $^{6}$; George Hripcsak ; David Vawdrey ${ }^{1,7}$

${ }^{1}$ Department of Biomedical Informatics, Columbia University, New York, NY;

${ }^{2}$ School of Interactive Computing, Georgia Institute of Technology, Atlanta, GA;

${ }^{3}$ University of Pennsylvania Health System, Pennsylvania, PA;

${ }^{4}$ College of Physicians and Surgeons, Columbia University Medical Center, New York, NY;

${ }^{5}$ School of Nursing, Columbia University, New York, NY;

${ }^{6}$ Department of Computer Science, Columbia University, New York, NY;

${ }^{7}$ NewYork-Presbyterian Hospital, New York, NY

\section{Keywords}

Patient engagement, inpatient, technology, personal health records

\section{Summary}

Objective: To investigate patients' experience using an inpatient personal health record (PHR) on a tablet computer to increase engagement in their hospital care.

Methods: We performed observations and conducted semi-structured interviews with 14 post-operative cardiac surgical patients and their family members who received an inpatient PHR. Themes were identified using an inductive coding scheme.

Results: All participants responded favorably to having access to view their clinical information. A majority (85.7\%) of participants used the application following an initial training session. Patients reported high satisfaction with being able to view their hospital medications and access educational materials related to their medical conditions. Patients reported a desire to view daily progress reports about their hospital stay and have access to educational information about their postacute recovery. In addition, patients expressed a common desire to view their diagnoses, laboratory test results, radiology reports, and procedure notes in language that is patient-friendly.

Conclusion: Patients have unmet information needs in the hospital setting. Our findings suggest that for some inpatients and their family members, providing personalized health information through a tablet computer may improve satisfaction, decrease anxiety, increase understanding of their health conditions, and improve safety and quality of care.

\section{Correspondence to:}

Janet Woollen

Columbia University, Department of Bioemdical Informatics

622 W. 168th St. PH-20

New York, NY 10032

United States of America

E-mail: jw3024@columbia.edu

\author{
Appl Clin Inform 2016; 7: 446-460 \\ http://dx.doi.org/10.4338/ACI-2015-10-RA-0130 \\ received: November 11, 2015 \\ accepted: March 15, 2016 \\ published: June 1, 2016 \\ Citation: Woollen J, Prey J, Wilcox L, Sackeim A, Res- \\ taino S, Raza ST, Bakken S, Feiner S, Hripcsak G, Vaw- \\ drey D. Patient experiences using an inpatient personal \\ health record. Appl Clin Inform 2016; 7: 446-460 \\ http://dx.doi.org/10.4338/ACI-2015-10-RA-0130
}




\section{Background}

Being a patient in the hospital is an anxiety-inducing experience. Poor communication and lack of access to information can have detrimental effects on a patient's psychological wellbeing and coping abilities [1-5]. Policymakers [6,7] and patient advocates [8,9] are increasingly focusing on this problem. This study investigates how an inpatient personal health record (PHR) may help address the information needs of patients and improve their engagement and experience in the hospital.

Provision of medical information and education about care can allay a patient's uncertainty and stress [10-15]. Further, sharing information has been shown to reduce patient requests for clinicians' time, foster a sense of control and empowerment while promoting self-efficacy and ownership of illness [16-18], and lead to increased participation as an informed partner in making health decisions [19-22]. Previous research suggests that patients want to use PHRs and believe that they will be valuable [23]. Moreover, patients believe that their adherence to treatment regimens will improve if they have the opportunity to read and understand their health information $[24,25]$. However, patients are not typically given the opportunity to review their health information in the hospital. For example, in a survey of hospitalized patients conducted by Cumbler and colleagues, $90 \%$ of respondents said they wanted to review their hospital medication list for accuracy, but only $28 \%$ said they were given the opportunity to do so[26]. Without access to a documented care plan, patients are uncertain as to the care they have received and what to expect. For example, studies show that patients remember less than half of what physicians explain to them in the hospital $[27,28]$. These findings suggest that there is potential to expand data-sharing practices with hospitalized patients in order to improve patient experience.

In previous work, we conducted a small pilot study where we provided a prototype of an inpatient PHR to five hospitalized patients in a supervised manner to assess their initial impressions and interest [38]. Using tablet computers, patients viewed photos of their care teams, medications they received, and their reconciled home medications and allergies. The response of patients and healthcare providers was positive $[38,39]$, demonstrating that the inpatient PHR could be a useful platform for addressing patients' information needs in the hospital. Based on the feedback we received from this earlier study, we enhanced the inpatient PHR system to address a number of limitations. The present study describes a larger deployment of the system and assesses patients' perceptions and information needs after having access to the technology without supervision for at least 24 hours during their hospital stay.

\section{Objectives}

The three aims of our study were to assess (1) the factors surrounding patients' use of an inpatient PHR, (2) patients' experience with the application, and (3) patients' information needs that might be partially met using an inpatient PHR.

\section{Methods}

\subsection{Setting and Technology}

In 2009, NewYork-Presbyterian Hospital (NYP) / Columbia University Medical Center (CUMC), a large urban academic medical center in New York City, implemented an outpatient portal called myNYP.org. In addition to functions such as the ability to search for NYP physicians, schedule appointments, and pay bills, the system allowed patients to access their laboratory test results, radiology reports, operative notes, and discharge summaries after leaving the hospital. In 2011, we developed a version of myNYP specifically for hospitalized patients. The initial inpatient PHR allowed patients and their families to view their care team (names, photos, and biographies), confirm allergies and home medications, and track hospital medications.

Based on the feedback from an earlier pilot study, we enhanced the inpatient PHR to increase usability and provide feature enhancements. These enhancements included user interface and navi- 
gation improvements, electronic self-reporting of pain level, and a feature to record notes, comments and questions for health providers that were made available to the care team within the hospital's electronic health record. Additionally, we made available links to medication information on MedlinePlus.gov, as well as links to curated educational content on myNYP.org, such as educational videos and explanations of medical conditions. A sample screen of the patient comment interface is shown in $>$ Figure 1.

\subsection{Study Design}

Patients and their family members from a post-operative cardiac surgery unit at NewYork-Presbyterian/Columbia University Medical Center were invited to participate in the study from August to December 2012. English-speaking participants were recruited based on consultation with the attending physician managing post-operative patients on the floor. Exclusion criteria included patients with severe mental illness, substance abuse, language barriers or severe physical discomfort. This study was approved by the Columbia University Medical Center Institutional Review Board.

After providing informed consent, participants were given an Apple iPad tablet computer with access to the inpatient PHR application. Initial use of the application was observed for 15 minutes to assess usability, answer questions, provide guidance on navigation of application, and collect initial impressions. The following day, participants participated in a semi-structured interview that took on average 20-30 minutes. The interview questions consisted of 23 questions based on core concepts from the Technology Acceptance Model [40]. To ensure accuracy of interpretations of interview data, we reflected back to participants our understanding of what we heard them reporting during the interviews [41]. Questions covered patients' demographics, technological adeptness, health information seeking behavior, knowledge of medical conditions, previous use of PHRs, information needs while in the hospital, and experience and use of the inpatient PHR application (see Appendix). Interviews were audio-recorded and transcribed by members of the research team, who met weekly to review general findings and themes of collected data. Participant recruitment continued until we reached thematic data saturation, i.e., when no new general themes were observed [42].

\subsection{Data Analysis}

Using a qualitative content analysis approach, two members of the research team (JW and AS) independently reviewed all the data and through the process of consensus building generated the coding scheme. They independently coded the data and discussed to clarify meaning and boundary of codes to finalize themes [43]. Participant demographics and self-reported usage of application were analyzed using descriptive statistics.

\section{Results}

Twenty-four patients were approached, twenty patients consented to participate in the study, and fourteen completed the semi-structured interviews ( Table 1). The mean age of the participants was 59.0 ( $\mathrm{SD}=16.0)$, with an equal split between male and female. The majority of participants (57.1\%) had at least some college education. Almost all participants (92.9\%) reported using the Internet on a daily basis and $21.4 \%$ had previous experience using a tablet computer. Three of the fourteen patients (21.4\%) used the inpatient PHR along with a family member.

Half of the participants (50.0\%) stated that they kept a physical file of their medical records at home. Nearly three-quarters of participants (71.4\%) reported searching online for health information from consumer health websites. Two of the fourteen patients (14.3\%) reported having access to their personal health information via a portal maintained by their provider. One patient reported having a digital copy of his records provided by his physician on a USB drive.

\subsection{Application Usage}

Most participants (85.7\%) reported using the application during the period after the initial observation session ( $>$ Table 2 ). The majority of participants (57.1\%) reported not using the tablet computer for other purposes (e.g., checking email, social media, browsing the Internet), even though they were 
invited to do so. The main factor patients reported that influenced their use of the application was their well-being. Patients reported feeling less inclined to use the application if they were experiencing pain or nausea, or had general malaise. In addition, patients who underwent multiple tests and/ or procedures reported less use. In several cases where the patient was too ill or otherwise disinclined to participate, a family member reported using the application (with the patient's permission).

In the small sample of participants, there were no apparent socio-demographic variables that impacted tablet usage. For example, there was no significant difference in application usage between female and male patients, and neither education level nor age played a role. However, we observed that patients who owned and used a tablet device previously had an easier time using the tablet and navigating through the application. Although most patients reported that the application was easyto-use, during initial observations, it was noted that about half had difficulty operating the tablet computer. After about 15 minutes of instruction, each of these participants reported feeling comfortable navigating the application.

\subsection{Patients' Experience with the Inpatient PHR}

Ten themes emerged from analysis of interviews: 1) desire to understand and engage, 2) desire for status report, 3) report test results, 4) ownership of data, 5) desire for guidance, 6) inpatient PHR serves as information and memory aid, 7) improves safety, 8) well-being affects use, 9) messaging providers: mixed response, 10) self-reporting pain: mostly unfavorable. Definitions of these themes and example quotes are further detailed in $>$ Table 3.

\subsection{Hospitalized Patients' Information Needs}

Thirteen of fourteen patients in the study (92.9\%) wanted more information about their hospital care, and the same number stated that the tablet-based inpatient PHR was helpful in addressing their information needs and valuable in increasing their understanding of their hospital stay. Some patients said they believed they should be given access to review any part of their medical record during their hospital stay, even if they cannot fully understand it. Though most participants pushed for greater access, $28.6 \%$ expressed hesitation about seeing sensitive material (e.g., a terminal prognosis) before their doctor could share it with them at an appropriate time. They felt safeguards should be put in place for sensitive information. Nearly half of participants (42.8\%) believed that in some instances, the application could replace face-to-face conversations with their providers.

\subsubsection{Information patients found most useful in the inpatient PHR}

Of the information provided in the inpatient PHR, the information reported as most useful was the list of hospital medications administered and links to educational materials. Specifically, 85.7\% of patients found the medication names and links to MedlinePlus.gov helpful for participating in and understanding their hospital care. For example, a potential medical error was prevented when a family member recognized a dosing error while using the application and notified the provider. Most participants also indicated that they liked seeing photos and short bios of their care team members as well.

\subsubsection{Additional information patients wanted}

In addition to what was accessible in the inpatient PHR, participants expressed interest in seeing their progress notes $(85.7 \%)$, operative reports (71.4\%), documented medical conditions (50\%), laboratory test results $(35.7 \%)$, and radiology reports $(35.7 \%)$. Participants were particularly interested in test results that were noted by their physicians to be important for discharge. Most participants desired more tailored information in the inpatient PHR, such as the following: a personalized care plan, a daily progress report, intended discharge date, key items providers needed to approve discharge, and a daily schedule (e.g., tests, procedures, and therapy sessions). Patients reported that this would help give them a sense of control over their day and help them plan when their guests should visit. Most participants requested educational information about their medical conditions and surgical procedure, along with self-care instructions and what to expect after discharge. In addition, a few 
patients wanted to be able to view information about their hospital bill and follow-up doctors appointments.

All participants reported wanting access to their records upon leaving the hospital. Some participants requested the ability to email their information to themselves or to their primary care provider. Several patients requested that information not typically part of a medical record be accessible outside the hospital or during their next hospital stay, such as viewing previous care team members. One patient wanted the ability to review ratings and provide reviews of exemplary staff members.

\section{Discussion}

This study explored hospital patients' usage, experience, and information needs using an inpatient PHR during their post-operative hospital stay. Participants uniformly responded favorably to having access to their clinical data and believed that the inpatient PHR was useful. The results of our study suggest that an inpatient PHR can be helpful to improve understanding, engagement, and safety for some patients in the hospital. These findings are consistent with the results of previous research investigating the effects of sharing medical information with patients through PHRs and patient portals in the outpatient setting $[17,19,44-49]$. Many patients want to play an active role in their care [8, $17,44,50]$, but patients cannot express informed preferences unless they are given sufficient and appropriate information about their medical care.

Our study adds to the limited research that has examined the benefits of providing hospitalized patients with access to their medical information and educational information.[29-36] There is still only a rudimentary understanding of how PHRs can contribute to improving inpatient experience and increasing patient engagement in the hospital setting.[37]

\subsection{Implications}

\subsubsection{Challenges}

Fulfilling patients' desires for personalized information about their hospital stay presents numerous challenges. Some of these challenges include determining what information is most beneficial to present to patients and choosing the format and context in which such information should be presented. Although patients wanted access to "everything," presenting the whole medical record (or even the many items requested by the study participants), may overwhelm rather than empower and truly inform. To avoid "information overload," considerable effort will be required to identify the most informative pieces of medical data that are meaningful to patients with various conditions and across various health services.

In order to fully explore the potential of inpatient participation and real-time sharing of medical records with inpatients, additional research is needed to determine how best to present medical record information to diverse patients. This is not a small challenge, as there are many factors that may influence patient interest and engagement with their health information and care [51]. For example, Weed proselytized the importance of format to profoundly help or hinder error discovery in and understanding of the medical record [52]. Key to maximizing understanding and engagement will be designing effective user interfaces [53]. Presenting medical record information to inpatients creates numerous new challenges: accommodating a patient's native language, health literacy level [54-56], information disclosure preferences [57-60], lack of familiarity with new technology, feelings of isolation and compromised constitution.

Providing daily "patient-friendly" progress reports as requested by participants may increase demands on clinicians to create and keep these reports up-to-date [61]. While clinicians typically write daily progress notes of patients for other clinicians, the content of these notes tends to be highly technical, is often in short form and is thick with abbreviations, reducing its informative value to patients. It is possible that existing technologies, such as natural language processing, could be leveraged to help interpret these notes to make them more accessible to patients and their families $[62,63]$.

Ensuring privacy is a significant challenge for an inpatient PHR. To protect electronic health information, security measures must be instituted to prevent access to unauthorized persons. How- 
ever, such measures (e.g., passwords) may hinder accessibility and convenience and, thus, use of an inpatient PHR. Passwords are easily forgotten, especially by impaired hospital patients. Additionally, patients have expressed a desire to have granular control over of their medical record.[20] New policies, logistics and technical challenges must be resolved in order to meet such desires without hampering usability, data sharing, or accessibility.

\subsubsection{Benefits}

From the interviews, we discovered how an inpatient PHR can bring value to hospitalized patients in five ways:

1. Facilitating data ownership: Patients view medical data as their property. Regardless of whether it is actionable or understandable, patients expressed it was their right to own and have ready access to their medical record. An inpatient PHR facilitates patients' feelings of ownership of their data.

2. Reducing uncertainty and anxiety: Study participants reported that receiving information about their care helped alleviate their uncertainty and stress by providing a sense of control.

3. Providing understandable information: Study participants appreciated the application's patientfriendly language, crediting it for helping them understand and take greater interest in their medical conditions. Additional work is needed to address issues of health literacy and numeracy, including providing information in a patient's preferred language[64];

4. Improving accuracy of data in the health record: Medical records can be inaccurate, incomplete, and biased.[65] With increased patient demand for access to medical records [8] and increased incentives to provide that access in recent federal legislation [7], more patients may review their medical records and help correct mistakes they discover [66]. Furthermore, this practice may motivate clinicians to improve data collection and documentation. Improving data quality and accuracy could in turn improve reuse of the data for secondary purposes such as quality improvement activities[67];

5. Improving patient safety: Providing patients with their medical information is beneficial for safety, as exemplified by a study participant in our study who intercepted a medication dosing error. An inpatient PHR may enable patients and family members help reduce medical errors, which have been identified as among America's leading causes of death [68].

\subsection{Suggestions for Future Research}

There remains a critical gap in the rigorous evaluation of inpatient PHRs to enhance patient engagement. Encouragingly, more health systems and an electronic medical records vendor have recently spearheaded studies of inpatient PHRs [34-36, 69, 70]. Further research is needed to clarify the appropriate design and implementation of these systems. Though usage in our study of the application was relatively high ( $86 \%$ of patients), it was a very high-touch intervention, with a research assistant spending considerable time educating patients about the technology and addressing concerns. Future research should help clarify what usage might be in a typical hospital ward.

The right balance must be struck between sharing all of a patient's record versus sharing information that is deemed useful, to avoid overwhelming patients with large volumes of data. Consideration must be given to policies of sharing sensitive test results or diagnoses before physicians can have conversations with their patients. Progress must also be made on creating user-interfaces and device ergonomics that take into consideration that "a hospital patient should be treated as a situationally-impaired user" [71], and their physical and mental state is likely to fluctuate over the course of a hospital stay. As part of this process, family members should also be considered as users, particularly for frail and elderly patients, and attention should be given to appropriate security and privacy controls when granting them access $[26,60]$.

Future research should quantify the benefits and negative consequences of patient-facing technologies at the bedside. Specifically, a „dose-response“ paradigm could be employed to determine whether the level of technology use is associated with changes in patient outcomes such as satisfaction, activation, health system utilization, readmission rates, and mortality. Randomized clinical trials should be conducted on a large and diverse inpatient population spanning a variety of healthcare settings (e.g., community hospital, long-term acute care, and academic medical center) to ensure results are widely applicable. 
Finally, in pursuing precision medicine's goal to take into account individuals' differences, future studies could characterize patient demographic traits associated with inpatient PHR usage patterns. Variability exists in patients' ability to handle the uncertainties and stress of a hospitalization. Accordingly, we anticipate an intervention like ours will be less compelling to patients who are relatively comfortable with uncertainty and have fewer information needs. Notwithstanding, family members may benefit, even if patients themselves do not wish to use the PHR system.

\subsection{Limitations}

This study had several limitations. First, it was a small qualitative study conducted in a single setting at a large academic medical center. All of the participants were post-operative cardiac surgical patients in the post-ICU step-down unit. These patients may not be representative of all hospitalized patients. Second, there is the potential for volunteer bias, as our study was a convenience sample of English-speaking patients who were mentally and physically stable. Twenty-four patients were approached, and fourteen patients completed interviews. This could lead us to overestimate the number of patients or family members that would use an inpatient PHR. Third, there is the potential for response bias since the study was not blinded and participants may have chosen to answer questions in a way they thought was favorable to the researchers. A subset of answers, such as to questions about participants' daily Internet use and the time participants spent interacting with the application, could have been subject to recall bias.

The impact of taking part in a formal study on inpatient PHRs may have had an effect on the amount that the tablet and inpatient PHR were used, as mentioned previously. With 14 patients, we did not have sufficient power to detect differences in usage based on sociodemographic variables. In addition, interviewer bias could have resulted in a more positive interpretation of participant responses than was shown in the data. We attempted to mitigate this last issue, by conducting two independent content analyses of the transcribed interviews and comparing results. Finally, inpatient PHRs may vary in content, usability, and function and thus the experience of participants in this study with the application may not generalize to experience with other inpatient PHR applications.

\section{Conclusion}

This study uncovered a high desire by inpatients to have access to information about their hospital care. Providing hospital patients access to an inpatient PHR may potentially help improve patient satisfaction, understanding of care, and safety. Our results highlight the need for further investigation of the optimal ways to share medical information with inpatients and the efficacy of inpatient PHRs in improving patient experience and health outcomes.

\section{Clinical Relevance Statement}

Patients have unmet information needs in the hospital setting. Providing hospitalized patients with personalized health information through a tablet computer may yield considerable benefits--improved data quality and patient safety, increased patient understanding of health conditions and hospital care processes, increased patient awareness of the recovery process, decreased patient stress, and increased patient satisfaction.

\section{Conflicts of Interest}

The authors have no competing interests to declare.

\section{Acknowledgments}

This project was supported by grants from the National Library of Medicine (T15 LM00707) and the Agency for Healthcare Research and Quality (R01HS21816).

\section{Human Subject Research Approval}

This study was approved by the Columbia University Medical Center Institutional Review Board. 


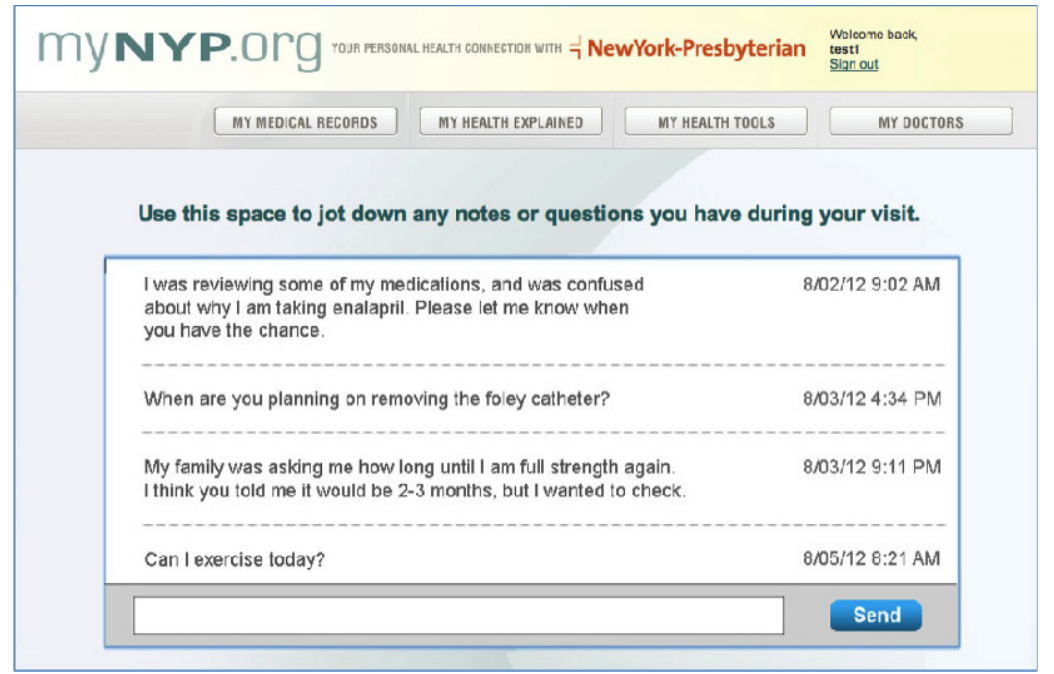

Fig. 1

Patient-entered questions and comments for the care team 


\begin{tabular}{|l|l|c|}
\hline Gender & Female & Overall (\%) \\
\hline Ages & $26-79$ & $7(50 \%)$ \\
\hline Education & High school or less & $2(14.3 \%)$ \\
\hline & Some college & $4(28.6 \%)$ \\
\hline College graduate & $8(57.1 \%)$ \\
\hline Exior Computer & Yes & $13(92.9 \%)$ \\
\hline Prior Tablet & No & $1(7.1 \%)$ \\
\hline Experience & No & $3(21.4 \%)$ \\
\hline Average Daily & Never & $11(78.6 \%)$ \\
\hline Internet Use & $1-30$ min/day & $1(7.1 \%)$ \\
\hline & $31-90$ min/day & $3(21.4 \%)$ \\
\hline$>90$ min/day & $6(43.9 \%)$ \\
\hline
\end{tabular}

Table 1

Participant Demographics and Technology Experience $(n=14)$

Overall (\%)

\section{Reported Inpatient PHR Use}

Did not use after observation period

$2(14.3 \%)$

0-15 mins

16-30 mins

$1-2$ hrs

$2(14.3 \%)$

\section{Reported Tablet Use for Other Purposes}

\begin{tabular}{|l|l|}
\hline No & $8(57.1 \%)$ \\
\hline Yes & $6(43.9 \%)$
\end{tabular}

\section{Table 2}

Participant Use of Inpatient PHR $(n=14)$

Table 3 Themes Related to Patients' Experience with the Inpatient PHR

\begin{tabular}{|c|c|c|}
\hline Themes & Description & Examples Quotes from Patients and Family Members \\
\hline $\begin{array}{l}\text { Desire to } \\
\text { Understand } \\
\text { and Engage }\end{array}$ & $\begin{array}{l}\text { An inpatient PHR } \\
\text { can help patients } \\
\text { and their families } \\
\text { learn about and en- } \\
\text { gage with their care. }\end{array}$ & $\begin{array}{l}\text { "I looked up the medicines to see what it does. I would have never known } \\
\text { what [the medicine] was." } \\
\text { "I can't believe I am taking all these medications." } \\
\text { "They started all kinds of new medications, and it was very easy for me to } \\
\text { go on the medication [page] and see the side effects. Instead of thinking } \\
\text { there is something else wrong with me I was able to say, 'Gee, well maybe } \\
\text { it's a side effect from this." } \\
\text { "I read about the whole procedure that I had, the cardiac bypass surgery, } \\
\text { and it's amazing exactly what happened and what they were able to do. } \\
\text { And I didn't really realize that because they use all these big terms, and } \\
\text { when you break it down to someone who is not medical, it's very interest- } \\
\text { ing." } \\
\text { "Access to their medical information gives patients and their caregivers } \\
\text { perspective and insight into their hospital care and empowers them with } \\
\text { knowledge about [what is going on], which reduces anxiety." }\end{array}$ \\
\hline
\end{tabular}


Table 3 Continued

\begin{tabular}{|c|c|c|}
\hline Themes & Description & Examples Quotes from Patients and Family Members \\
\hline $\begin{array}{l}\text { Desire for } \\
\text { Status Report }\end{array}$ & $\begin{array}{l}\text { Inpatients want in- } \\
\text { formation concern- } \\
\text { ing their health } \\
\text { status and recovery } \\
\text { progress. }\end{array}$ & $\begin{array}{l}\text { "When am I getting out of here?...What progress am I making?" } \\
\text { "Like right now, [I would like my care team to tell me] what's my plan? 'All } \\
\text { x-rays are good. We are now waiting for your INRs to reach the level of } 3 . \\
\text { It is now at a level of } 2.5 \text {. So hopefully we can increase the heparin do- } \\
\text { sage and by tomorrow it should reach it, and you should be discharged."' }\end{array}$ \\
\hline $\begin{array}{l}\text { Report Test } \\
\text { Results }\end{array}$ & $\begin{array}{l}\text { Inpatients want to } \\
\text { learn about their } \\
\text { diagnostic tests and } \\
\text { see their results. }\end{array}$ & $\begin{array}{l}\text { "If [the clinician] is performing a procedure on me, I don't know what the } \\
\text { hell it is called." } \\
\text { "He's had x-rays and blood draws and I would like to see the results." } \\
\text { "I know they were giving him phosphorous, so I would like to see what } \\
\text { the levels were." }\end{array}$ \\
\hline $\begin{array}{l}\text { Ownership of } \\
\text { data }\end{array}$ & $\begin{array}{l}\text { Inpatients consider } \\
\text { their medical record } \\
\text { as something they } \\
\text { have a right to own. }\end{array}$ & $\begin{array}{l}\text { "I think if it pertains to them, they should have anything that they want. } \\
\text { It's your record." } \\
\text { "Everything." }\end{array}$ \\
\hline $\begin{array}{l}\text { Desire for } \\
\text { Guidance }\end{array}$ & $\begin{array}{l}\text { Inpatients want in- } \\
\text { structions about } \\
\text { what to do and ex- } \\
\text { pect in and out of } \\
\text { the hospital. }\end{array}$ & $\begin{array}{l}\text { "I just had open heart surgery, something saying...the feelings you might } \\
\text { experience, how long the feelings may be there for...things you have to } \\
\text { do, how long you have to do it. The road to recovery." } \\
\text { "You want to go home knowledgeable. If I could have a tablet... where I } \\
\text { could see..., Dad had this, this, and this. This is what you should be looking } \\
\text { for. That would be ideal. That's what I want." }\end{array}$ \\
\hline $\begin{array}{l}\text { Inpatient } \\
\text { PHR Serves } \\
\text { as Informa- } \\
\text { tion and } \\
\text { Memory Aid }\end{array}$ & $\begin{array}{l}\text { Inpatients' questions } \\
\text { can go unattended } \\
\text { for long periods and } \\
\text { can be missed or for- } \\
\text { gotten. An inpatient } \\
\text { PHR could serve as } \\
\text { an informative agent } \\
\text { covering the time } \\
\text { between provider vi- } \\
\text { sits. }\end{array}$ & $\begin{array}{l}\text { "It's great cause I can look up all my questions and I won't forget any- } \\
\text { thing." } \\
\text { "I always am under the impression that doctors are busy people; they } \\
\text { can't just stop and come to see me and explain things to me." } \\
\text { "A lot of times doctors come in and tell you } 20 \text { things and out of the } 20 \\
\text { things you'll only remember like } 1 \text { or } 2 \text {. So you're like, 'What the hell did } \\
\text { he say? I forgot what he said.'" } \\
\text { "I had problems naming doctors because so many of them come to my } \\
\text { room." } \\
\text { "[The inpatient PHR is an] awesome idea because if you are sitting in bed } \\
\text { and you have a question often times you forget it by the next day." }\end{array}$ \\
\hline $\begin{array}{l}\text { Improves } \\
\text { Safety }\end{array}$ & $\begin{array}{l}\text { Patients and family } \\
\text { members can use } \\
\text { the application to } \\
\text { prevent errors. }\end{array}$ & $\begin{array}{l}\text { "I like it because I discovered yesterday a medication he's getting that he } \\
\text { is taking at home, and they're actually giving him half the dose he's get- } \\
\text { ting at home." } \\
\text { (A family member recognized a dosing error while using the application. } \\
\text { She alerted a nurse and the medication was changed to the appropriate } \\
\text { dose.) }\end{array}$ \\
\hline $\begin{array}{l}\text { Well-being } \\
\text { Affects Use }\end{array}$ & $\begin{array}{l}\text { Patients' lack of } \\
\text { well-being affects } \\
\text { use and interest in } \\
\text { the application. }\end{array}$ & $\begin{array}{l}\text { "When you first come in you might be too damn sick to really care about } \\
\text { it or read the formalities. You have to be feeling better." } \\
\text { "I was very nauseous and not feeling well so I really wasn't up to using it. } \\
\text { Started this morning, trying to look at it a little bit because I was feeling } \\
\text { better... if you're not feeling well you're not going to really be using it be- } \\
\text { cause you're not up to it... you don't have the energy." }\end{array}$ \\
\hline
\end{tabular}


Table 3 Continued

\begin{tabular}{|c|c|c|}
\hline Themes & Description & Examples Quotes from Patients and Family Members \\
\hline $\begin{array}{l}\text { Messaging } \\
\text { Providers: } \\
\text { Mixed Re- } \\
\text { sponse }\end{array}$ & $\begin{array}{l}\text { Inpatient-provider } \\
\text { communication via } \\
\text { electronic messaging } \\
\text { may be beneficial for } \\
\text { some and ignored by } \\
\text { others. }\end{array}$ & $\begin{array}{l}\text { "Me personally, I don't need to see you. I just want to text you." } \\
\text { "I think it's a good thing - if they answer, some of them aren't online to } \\
\text { answer. I think we should be able to email our doctors all the time. I don't } \\
\text { care where they at. They always got computers, iPhones, whatever." } \\
\text { "[Doctors] are not going to be available sitting down at the desk the } \\
\text { whole entire day. They're going back and forth, so...they're just not going } \\
\text { to have time to [answer questions]." } \\
\text { "It would be nice to have the communication face-to-face, but for some } \\
\text { questions like about meds [it] might be quicker to text the doctor." } \\
\text { "I don't think it's a good idea. The doctor is supposed to see the patient, } \\
\text { sometimes feel them." } \\
\text { "I just think it'd be nice if I [sent a message] and then they said, 'I'Il be } \\
\text { with you in ten minutes,' or something." }\end{array}$ \\
\hline $\begin{array}{l}\text { Self-Report- } \\
\text { ing Pain: } \\
\text { Mostly unfa- } \\
\text { vorable }\end{array}$ & $\begin{array}{l}\text { Although some par- } \\
\text { ticipants thought en- } \\
\text { tering pain scores in } \\
\text { the application could } \\
\text { replace or supple- } \\
\text { ment clinician pain } \\
\text { assessments, most } \\
\text { participants did not } \\
\text { think self-reporting } \\
\text { pain scores would be } \\
\text { advantageous. }\end{array}$ & $\begin{array}{l}\text { "If I say I need pain medication and I enter it and tell you - and enter it as } \\
\text { a } 6 \text { or a } 7 \text { - then I guess the nurse can determine how quick she has to get } \\
\text { to me. So maybe it's a good thing." } \\
\text { "I don't know the benefit that would do. Because if you're in pain all you } \\
\text { do is ask the nurse, I'm in pain and they'll ask you } 1 \text { to } 5 \text {, it's a 4, and } \\
\text { they'll assign you some medication. It's very simple." } \\
\text { "No. You know why? Because I want to see [that] the nurse knows." }\end{array}$ \\
\hline
\end{tabular}




\section{Appendix Interview Questions}

\section{User Background}

1. What is your age? Record gender as well.

2. What is your profession? Level of education?

3. Do you know your medical conditions? Do you know your medications and what they do? How knowledgeable would you say you are about your health?

4. Do you have a smartphone? How much time do you spend each day using the internet or apps on your smartphone on average?

5. Do you have a desktop or laptop computer? Do you have internet on your computer? How much time do you spend each day on your computer on average?

6. Do you have a tablet computer? How much time do you spend each day on your tablet on average?

7. Do you have a personal health record? Who do you use it for (self, children, parents)? How frequently do you use it?

8. Do you look up information about your health online? What websites do you use?

\section{General Inpatient PHR Questions}

1. What do you think about patients receiving an inpatient personal health record like the one you used?

2. What information do you think patients would like to see while they are in the hospital?

3. What information should patients not have access to?

4. What questions have you asked your doctors while in the hospital? What do you think about patients being able to ask questions or make comments to their care team in the application? Is this useful?

5. Should this be one-way or two-way communication? (ie should the patient send messages in which a member of the care team responds in person, or should patients and the care team communicate electronically through the application).

6. What do you think about patients entering their own pain scores? Could this replace the scores recorded by nursing?

7. Patient's will still have access to their records when they leave, but how long should patients have access to the special features of the inpatient PHR, such as staff profiles or ability message with your team, after the hospital stay?

\section{Questions about application (myNYP)}

1. What do you think about the myNYP Inpatient application?

2. What was most useful about the application? What was least useful?

3. What do you think if anything is missing from the application? What do you wish we had included?

4. Was it easy to find what you needed? Did you find navigating through the application confusing?

5. Was the information accurate?

6. What did you think about $\mathrm{x}$ (care team, hospital medications, allergies, home medications, notepad, pain)? What would you add or change to them? (If they did not use it, show it to them and ask for their opinion)

7. Was the text the right size? How was it entering notes on the iPad?

8. How much time would you say you spent looking at the application? What else did you use the iPad while you had it? (We want to get a sense of what patients might use iPad for apart from our application) 


\section{References}

1. Gammon. Analysis of the stressful effects of hospitalisation and source isolation on coping and psychological constructs: Coping and psychological constructs. Int J Nurs Pract 2008; 4(2): 84-96.

2. Thompson DR. A randomized controlled trial of in-hospital nursing support for first time myocardial infarction patients and their partners: effects on anxiety and depression*. J Adv Nurs 1989; 14(4): 291-297.

3. Elliott D. Measuring patient anxiety in coronary care. Aust Crit Care 1992; 5(2): 12-16.

4. Teasdale K. Information and anxiety: a critical reappraisal. J Adv Nurs 1993; 18(7): 1125-1132.

5. Shuldham CM, Cunningham G, Hiscock M, Luscombe P. Assessment of anxiety in hospital patients. J Adv Nurs 1995; 22(1): 87-93.

6. Baker A. Crossing the Quality Chasm: A New Health System for the 21st Century. BMJ 2001; 323(7322): 1192.

7. Neuner J, Fedders M, Caravella M, Bradford L, Schapira M. Meaningful Use and the Patient Portal Patient Enrollment, Use, and Satisfaction With Patient Portals at a Later-Adopting Center. Am J Med Qual 2014 Feb 21; 1062860614523488.

8. deBronkart D. How the e-patient community helped save my life: an essay by Dave deBronkart. BMJ 2013; 346(apr02 1): f1990-f1990.

9. Terry SF. Life as a numerator: Putting the person in personal genomics. Appl Transl Genomics. [cited 2016 Feb 22]; Available from: http://www.sciencedirect.com/science/article/pii/S2212066116300072

10. Bondy LR, Sims N, Schroeder DR, Offord KP, Narr BJ. The effect of anesthetic patient education on preoperative patient anxiety. Reg Anesth Pain Med 1999; 24(2): 158-164.

11. Guo P, East L, Arthur A. A preoperative education intervention to reduce anxiety and improve recovery among Chinese cardiac patients: a randomized controlled trial. Int J Nurs Stud 2012; 49(2): 129-137.

12. Kiyohara LY, Kayano LK, Oliveira LM, Yamamoto MU, Inagaki MM, Ogawa NY, et al. Surgery information reduces anxiety in the pre-operative period. Rev Hosp Clin Fac Med Sao Paulo 2004; 59(2): 51-56.

13. Luck A, Pearson S, Maddem G, Hewett P. Effects of video information on precolonoscopy anxiety and knowledge: a randomised trial. The Lancet 1999; 354(9195): 2032-2035.

14. Marteau TM, Kidd J, Cuddeford L, Walker P. Reducing anxiety in women referred for colposcopy using an information booklet. Br J Health Psychol 1996; 1(2): 181-189.

15. Dennis KE. Dimensions of Client Control. Nurs Res 1987; 36(3): 151-155.

16.Lin C-T, Wittevrongel L, Moore L, Beaty BL, Ross SE. An Internet-Based Patient-Provider Communication System: Randomized Controlled Trial. J Med Internet Res 2005; 7(4): e47.

17.Edgman-Levitan S, Cleary PD. What information do consumers want and need? Health Aff (Millwood). 1996; 15(4): 42-56.

18. Pell J, Mancuso M, Limon S, Oman K, Lin C. Patient access to electronic health records during hospitalization. JAMA Intern Med 2015; 175(5): 856-858.

19.Tang PC, Newcomb C. Informing Patients A Guide for Providing Patient Health Information. J Am Med Inform Assoc 1998; 5(6): 563-570.

20. Caine K, Hanania R. Patients want granular privacy control over health information in electronic medical records. J Am Med Inform Assoc JAMIA 2013; 20(1): 7-15.

21. Delbanco TL, Stokes DM, Cleary PD, Edgman-Levitan S, Walker JD, Gerteis M, et al. Medical patients' assessments of their care during hospitalization: insights for internists. J Gen Intern Med 1995; 10(12): 679-685.

22. Doherty C, Stavropoulou C. Patients' willingness and ability to participate actively in the reduction of clinical errors: a systematic literature review. Soc Sci Med 19822012 Jul; 75(2): 257-263.

23. Civan A, Skeels MM, Stolyar A, Pratt W. Personal Health Information Management: Consumers' Perspectives. AMIA Annu Symp Proc 2006; 2006: 156-160.

24.Bronson DL, Rubin AS, Tufo HM. Patient education through record sharing. QRB Qual Rev Bull 1978; 4(12): $2-4$.

25. Blinder D, Rotenberg L, Peleg M, Taicher S. Patient compliance to instructions after oral surgical procedures. Int J Oral Maxillofac Surg 2001; 30(3): 216-219.

26. Cumbler E, Wald H, Kutner J. Lack of patient knowledge regarding hospital medications. J Hosp Med 2010; 5(2): 83-86.

27. Calkins DR, Davis RB, Reiley P, et al. Patient-physician communication at hospital discharge and patients' understanding of the postdischarge treatment plan. Arch Intern Med 1997; 157(9): 1026-1030.

28. Bronson DDL, O'Meara K. The impact of shared medical records on smoking awareness and behavior in ambulatory care. J Gen Intern Med 1986; 1(1): 34-37. 
29. Kim E-H, Stolyar A, Lober WB, Herbaugh AL, Shinstrom SE, Zierler BK, et al. Challenges to Using an Electronic Personal Health Record by a Low-Income Elderly Population. J Med Internet Res 2009; 11(4): e44.

30.Tsai J, Rosenheck RA. Use of the internet and an online personal health record system by US veterans: comparison of Veterans Affairs mental health service users and other veterans nationally. J Am Med Inform Assoc 2012; 19(6): 1089-1094.

31. Archer N, Fevrier-Thomas U, Lokker C, McKibbon KA, Straus SE. Personal health records: a scoping review. J Am Med Inform Assoc 2011; 18(4): 515-522.

32. Hourcade JP, Chrischilles EA, Gryzlak BM, Hanson BM, Dunbar DE, Eichmann DA, et al. Design Lessons for Older Adult Personal Health Records Software from Older Adults. In: Stephanidis C, editor. Universal Access in Human-Computer Interaction Users Diversity [Internet]. Springer Berlin Heidelberg; 2011 [cited 2014 Jan 5]. p. 176-85. Available from: http://link.springer.com/ chapter/10.1007/978-3-642-21663-3_19

33. Caligtan CA, Carroll DL, Hurley AC, Gersh-Zaremski R, Dykes PC. Bedside information technology to support patient-centered care. Int J Med Inf 2012; 81(7): 442-451.

34. Dykes PC, Carroll DL, Hurley AC, Benoit A, Chang F, Pozzar R, et al. Building and Testing a Patient-Centric Electronic Bedside Communication Center. J Gerontol Nurs 2013; 39(1): 15-19.

35. Greysen SR, Khanna RR, Jacolbia R, Lee HM, Auerbach AD. Tablet computers for hospitalized patients: A pilot study to improve inpatient engagement. J Hosp Med 2014; 9(6): 396-399.

36. Pell J, Mancuso M, Limon S, Oman K, Lin C. Patient access to electronic health records during hospitalization. JAMA Intern Med 2015; 175(5): 856-858.

37.Prey JE, Woollen J, Wilcox L, Sackeim AD, Hripcsak G, Bakken S, et al. Patient engagement in the inpatient setting: a systematic review. J Am Med Inform Assoc 2013 Nov 22;amiajnl - 2013-002141.

38. Vawdrey DK, Wilcox LG, Collins SA, Bakken S, Feiner S, Boyer A, et al. A Tablet Computer Application for Patients to Participate in Their Hospital Care. AMIA Annu Symp Proc 2011; 2011: 1428-1435.

39. Wilcox L, Feiner S, Liu A, Restaino S, Collins S, Vawdrey D. Designing Inpatient Technology to Meet the Medication Information Needs of Cardiology Patients. Proceedings of the 2Nd ACM SIGHIT International Health Informatics Symposium. New York, NY, USA: ACM; 2012 [cited 2014 Feb 27]. p. 831-6. Available from: http://doi.acm.org/10.1145/2110363.2110466

40.Davis FD. Perceived Usefulness, Perceived Ease of Use, and User Acceptance of Information Technology. MIS Q 1989; 13(3): 319-340.

41. Morse JM, Barrett M, Mayan M, Olson K, Spiers J. Verification Strategies for Establishing Reliability and Validity in Qualitative Research. Int J Qual Methods 2008; 1(2): 13-22.

42. Guest G, Bunce A, Johnson L. How Many Interviews Are Enough? An Experiment with Data Saturation and Variability. Field Methods 2006; 18(1): 59-82.

43. Elo S, Kyngäs H. The qualitative content analysis process. J Adv Nurs 2008; 62(1): 107-115.

44. Businger A, Buckel L, Gandhi T, Grant R, Poon E, Schnipper J, et al. Patient review of selected electronic health record data improves visit experience. AMIA Annu Symp Proc AMIA Symp AMIA Symp 2007; 887.

45. Delbanco T, Walker J, Bell SK, Darer JD, Elmore JG, Farag N, et al. Inviting Patients to Read Their Doctors' Notes: A Quasi-experimental Study and a Look Ahead. Ann Intern Med 2012; 157(7): 461-470.

46. Berg M, Langenberg C, Kwakkernaat J. Considerations for sociotechnical design: experiences with an electronic patient record in a clinical context. Int J Med Inf 1998; 52(1): 243-251.

47. Hassol A, Walker JM, Kidder D, Rokita K, Young D, Pierdon S, et al. Patient experiences and attitudes about access to a patient electronic health care record and linked web messaging. J Am Med Inform Assoc JAMIA 2004; 11(6): 505-513.

48. Keselman A, Slaughter L, Arnott-Smith C, Kim H, Divita G, Browne A, et al. Towards Consumer-Friendly PHRs: Patients' Experience with Reviewing Their Health Records. AMIA Annu Symp Proc 2007; 2007: 399.

49. Weingart SN, Rind D, Tofias Z, Sands DZ. Who Uses the Patient Internet Portal? The PatientSite Experience. J Am Med Inform Assoc 2006; 13(1): 91-95.

50. Trewin VF, Veitch GBA. Patient sources of drug information and attitudes to their provision: a corticosteroid model. Pharm World Sci 2003; 25(5): 191-196.

51. Galesic M, Garcia-Retamero R. Do low-numeracy people avoid shared decision making? Health Psychol 2011; 30(3): 336-341.

52. Weed LL. Quality control and the medical record. Arch Intern Med 1971; 127(1): 101-105.

53.Zarcadoolas C, Vaughon WL, Czaja SJ, Levy J, Rockoff ML. Consumers' Perceptions of Patient-Accessible Electronic Medical Records. J Med Internet Res 2013; 15(8): e168. 
54.Sarkar U, Karter AJ, Liu JY, Adler NE, Nguyen R, López A, et al. The Literacy Divide: Health Literacy and the Use of an Internet-Based Patient Portal in an Integrated Health System - Results from the Diabetes Study of Northern California (DISTANCE). J Health Commun 2010; 15(sup2): 183-196.

55. Baum S. Can making data beautiful engage patients and boost health literacy? [Internet]. MedCity News. 2013 [cited 2014 Jan 19]. Available from: http://medcitynews.com/2013/05/can-making-data-beautifulengage-patients-and-boost-health-literacyvideo/

56. Noblin AM, Wan TTH, Fottler M. The Impact of Health Literacy on a Patient's Decision to Adopt a Personal Health Record. Perspect Health Inf Manag AHIMA Am Health Inf Manag Assoc. 2012 Fall [cited 2013 Dec 15]; 9(Fall). Available from: /pmc/articles/PMC3510648/?report=abstract

57. Faden RR, Becker C, Lewis C, Freeman J, Faden AI. Disclosure of Information to Patients in Medical Care. Med Care 1981; 19(7): 718-733.

58. Fielding R, Wong L, Ko L. Strategies of information disclosure to Chinese cancer patients in an Asian community. Psychooncology 1998; 7(3): 240-251.

59. Mazur DJ. Information Disclosure and Beyond: How Do Patients Understand and Use the Information They Report They Want? Med Decis Making 2000; 20(1): 132-134.

60. Mystakidou K, Parpa E, Tsilika E, Katsouda E, Vlahos L. Cancer information disclosure in different cultural contexts. Support Care Cancer 2003; 12(3): 147-154.

61. Dalal AK, Dykes PC, Collins S, Lehmann LS, Ohashi K, Rozenblum R, et al. A web-based, patient-centered toolkit to engage patients and caregivers in the acute care setting: a preliminary evaluation. J Am Med Inform Assoc 2015 Aug 2; ocv093.

62.Zeng-Treitler Q, Goryachev S, Kim H, Keselman A, Rosendale D. Making Texts in Electronic Health Records Comprehensible to Consumers: A Prototype Translator. AMIA Annu Symp Proc 2007; 2007: 846-850.

63. Keselman A, Logan R, Smith CA, Leroy G, Zeng-Treitler Q. Developing Informatics Tools and Strategies for Consumer-centered Health Communication. J Am Med Inform Assoc 2008; 15(4): 473-483.

64. Wilkins V, Elliott MN, Richardson A, Lozano P, Mangione-Smith R. The Association between Care Experiences and Parent Ratings of Care for Different Racial, Ethnic, and Language Groups in a Medicaid Population. Health Serv Res 2011; 46(3): 821-839.

65. Weiskopf NG, Hripcsak G, Swaminathan S, Weng C. Defining and measuring completeness of electronic health records for secondary use. J Biomed Inform 2013; 46(5): 830-836.

66. Siteman E, Businger A, Gandhi T, Grant R, Poon E, Schnipper J, et al. Physicians value patient review of their electronic health record data as a means to improve accuracy of medication list documentation. AMIA Annu Symp Proc AMIA Symp AMIA Symp 2007; 1116.

67. Hack TF, Degner LF, Dyck DG. Relationship between preferences for decisional control and illness information among women with breast cancer: A quantitative and qualitative analysis. Soc Sci Med 1994; 39(2): 279-289.

68. Hayward RA, Hofer TP. Estimating hospital deaths due to medical errors: Preventability is in the eye of the reviewer. JAMA 2001; 286(4): 415-420.

69. Comstock J. KP discharge app is early step in future care vision | mobihealthnews. Mobihealthnews.com. 2014 [cited 2015 Jan 20]. Available from: http://mobihealthnews.com/30287/kps-discharge-app-is-earlystep-in-future-care-vision/

70.Dolan B. Ohio medical center discusses mobile first strategy and Epic's MyChart Bedside iPad app. 2014 Feb 26;

71.Morris D, Karlson A. Dynamic Accessibility Requirements for Hospital Patients. SIGCHI Computing Conference on Human Factors in Systems [Internet].; 2011. Available from: http://research.microsoft.com/enus/um/redmond/groups/cue/publications/Morris_Karlson_CHI_2011_Dynamic_Accessibilit Y_Workshop.pdf

72. Sarkar U, Bates DW. Care partners and online patient portals. JAMA 2014; 311(4): 357-358. 